\title{
A NUMERICAL METHOD FOR FREE VIBRATION OF AXIALLY LOADED COMPOSITE TIMOSHENKO BEAM
}

\author{
Aleksandar Prokić * , Miroslav T. Bešević and Martina Vojnić-Purčar \\ Faculty of Civil Engineering, University of Novi Sad, Kozaračka 2a, 24000 Subotica, Serbia \\ *(Corresponding author: E-mail: aprokic@eunet.rs)
}

Received: 13 February 2014; Revised: 17 December 2014; Accepted: 14 January 2015

\begin{abstract}
In this paper, a numerical method is employed to study the free vibration of axially loaded composite Timoshenko beam. The problem is governed by a set of coupled second-order ordinary differential equations of motion, under different boundary conditions. The method is based on numerical integration rather than the numerical differentiation since the highest derivatives of governing functions are chosen as the basic unknown quantities. The kernels of integral equations turn out to be Green's function of corresponding equation with homogeneous boundary conditions. The accuracy of the proposed method is demonstrated by comparing the calculated results with those available in the literature. It is shown that good accuracy can be obtained even with a relatively small number of nodes.
\end{abstract}

Keywords: Numerical method, Green's function, Vibration, Timoshenko beam, Integral equations

DOI: $10.18057 /$ IJASC.2016.12.1.5

\section{INTRODUCTION}

Composite thin-walled beams are widely used as structural elements in many types of structures. Compared to standard construction materials, composite materials present many advantages, e.g. light weight, corrosion resistance, low thermal expansion, and excellent fatigue characteristics in the direction of the fibers. Because of their practical importance the accurate prediction of the dynamic behavior of such constructions is an important part of engineering analysis.

When cross-sectional dimensions are large or higher frequencies are studied in the vibration analysis of the composite beams, the effects of shear deformation and rotary inertia should be taken into account, i.e. Timoshenko's beam model should be used. The effect of axial load adds some additional terms to the equations of motion of the Timoshenko beam and so they become more complicated to solve and numerical methods have to be applied. Numerical methods such as finite element (Reddy [17], Vo et al. [18], Borbon et al. [6]) finite difference (Fule and Zhi-zhong [8], Ansari et al. [1]) differential quadrature (Mirtalaie et al. [13], Rajasekeran [16]), the dynamic stiffness matrix (Benerjee [2 3], Li et al. [11], Pagani et al. [14]) and some other methods (Biscontin et al. [5], Berczynski and Wroblewski [4], Pan et al. [15], Liu et al. [12]) have been used in solving free vibration problems of structures.

In this study a numerical method is developed for free vibration analysis of an axially loaded composite Timoshenko beam with bending-torsional coupling. The highest derivatives in the differential equations are chosen as the basic unknowns of the problem, as it was first proposed by Hajdin [9], and the unknowns are determined through the corresponding integral equations. In the formation of integral equations we use methods that are well known to engineers from the theory of structures, as Green's functions are nothing more than well-known influence function of a beam. Finally, by the application of the numerical integration it is possible to replace that equations into linear algebraic equations from which can be obtained a characteristic equation of natural 
frequencies, for different boundary conditions. With a relatively small number of points it can be achieved satisfactory accuracy of the results.

\section{THEORETICAL CONSIDERATIONS}

A straight Timoshenko beam of length 1 with a solid rectangular cross-section is considered. A constant axial load $\mathrm{P}$ is assumed to act through the centroid (mass centre) of the cross section. $\mathrm{P}$ is considered to be positive when it is compressive. The flexural displacement, in the y direction and the torsional rotation about the $\mathrm{z}$-axis are denoted by $v(z, t)$ and $\varphi(z, t)$ respectively, where $\mathrm{z}$ and $\mathrm{t}$ denote distance from the origin and time. The rotation of the cross-section about the y-axis due to flexure alone is denoted by $\psi(z, t)$.

The governing partial differential equations of motion of the axially loaded Timoshenko beam exhibiting coupled flexure-torsion free natural vibration are given by Kaya and Ozgumus [10]

$$
\begin{aligned}
& E I_{y} \psi^{\prime \prime}+k F G\left(v^{\prime}-\psi\right)+K \varphi^{\prime \prime}-\rho I_{y} \ddot{\psi}=0 \\
& k F G\left(v^{\prime \prime}-\psi^{\prime}\right)-m \ddot{v}-P v^{\prime \prime}=0 \\
& K \psi^{\prime \prime}-P\left(\frac{I_{s}}{m}\right) \varphi^{\prime \prime}+G J \varphi^{\prime \prime}-I_{s} \ddot{\varphi}=0
\end{aligned}
$$

where primes and dots denote differentiation with respect to coordinate $z$ and time $t$, respectively; $\rho$ is the material density; $F$ the cross sectional area; $I_{y}$ the second moment of inertia of the beam cross section about the $y$-axis; $m=\rho F$ is the mass per unit length; $I_{s}$ the polar mass moment of inertia per unit length about the $z$-axis. $E I_{y}, G J, K$ and $k G F$ are the flexural rigidity, torsional rigidity, flexure-torsion coupling rigidity and shear rigidity of the composite beam, respectively. Eqs. 1 together with appropriate end conditions $(z=0$ and $z=l)$ completely define the coupled bending-torsion free vibration of an axially loaded uniform Timoshenko beam.

If a sinusoidal variation of $v(z, t), \psi(z, t)$ and $\varphi(z, t)$ with circular frequency $\omega$, is assumed, then

$$
\begin{aligned}
& v(z, t)=V(z) \sin \omega t \\
& \psi(z, t)=\Psi(z) \sin \omega t \\
& \varphi(z, t)=\Phi(z) \sin \omega t
\end{aligned}
$$

where $V(z), \Psi(z)$ and $\Phi(z)$ are the amplitudes of the sinusoidal varying vertical displacement, flexural rotation and torsion rotation, respectively.

Substituting Eqs. 2 into Eqs. 1, equations of motion can be rewritten as follows:

$$
\begin{aligned}
& E I_{y} \Psi^{\prime \prime}+k F G\left(V^{\prime}-\Psi\right)+K \Phi^{\prime \prime}+\rho I_{y} \omega^{2} \Psi=0 \\
& k F G\left(V^{\prime \prime}-\Psi^{\prime}\right)+m \omega^{2} V-P V^{\prime \prime}=0 \\
& K \Psi^{\prime \prime}-P\left(\frac{I_{s}}{m}\right) \Phi^{\prime \prime}+G J \Phi^{\prime \prime}+I_{s} \omega^{2} \Phi=0
\end{aligned}
$$

or in the matrix form

$$
\mathbf{A q} \mathbf{q}^{\prime \prime}+\mathbf{B} \mathbf{q}^{\prime}+\left(\mathbf{C}+\omega^{2} \mathbf{D}\right) \mathbf{q}=\mathbf{0}
$$


where displacement state vector $\mathbf{q}$, consisting of 3 displacement parameters, is defined by

$\mathbf{q}=\left[\begin{array}{l}q_{1} \\ q_{2} \\ q_{3}\end{array}\right]=\left[\begin{array}{l}V(z) \\ \Psi(z) \\ \Phi(z)\end{array}\right]$

and matrices $\mathbf{A}, \mathbf{B}, \mathbf{C}$ and $\mathbf{D}$ are as follows

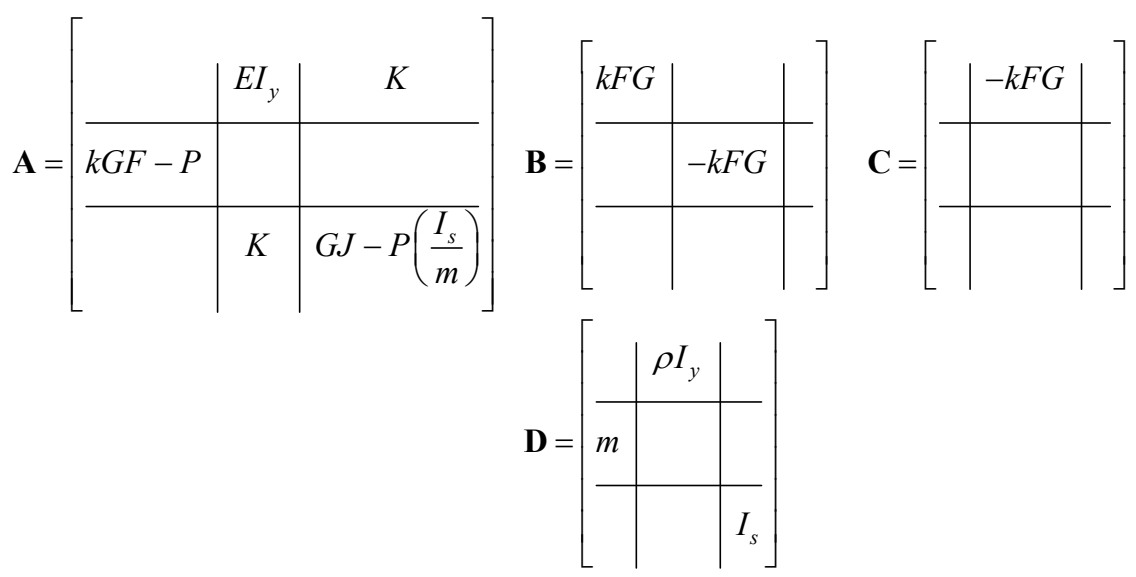

\section{INTEGRAL EQUATION METHOD}

The second derivatives of any component $q_{i}(i=1,2$ and 3$)$ of vector $\mathbf{q}$ shall be denoted

$q_{i}^{\prime \prime}=-p_{i}(z)$

In addition to differential Eq. 6 the following boundary conditions are given

for $z=0\left\{\begin{array}{l}q_{i}=q_{i 0} \\ q_{i}^{\prime}=q_{i 0}^{\prime}\end{array}\right.$

The solution to Eq. 6 may be written as (Byron and Fuller [7])

$q_{i}(z)=\int s(z, \varsigma) p_{i}(\varsigma) d \varsigma+q_{i 0}^{\prime} z+q_{i 0}$

where $\varsigma$ is the integration variable and $s(s, \varsigma)$ is Green's function corresponding to the differential Eq. 6, which obeys homogeneous boundary conditions Eq. 7. Function $s(s, \varsigma)$, known as kernel of integral Eq. 8, is defined by

$s(z, \varsigma)=\left\{\begin{array}{cc}-(z-\varsigma) & \varsigma \leq z \\ 0 & \varsigma>z\end{array}\right.$

If $p_{i}(z)$ is understood as external transverse load distributed along the axis of the beam, $q_{i 0}$ and $q_{i 0}^{\prime}$ as a bending moment and a transversal force, respectively, at the left end of the beam, and $q_{i}(z)$ as bending moment along the beam, than integral Eq. 8 defines the dependence between the cross section forces and external load of the fictitious cantilever beam of length $l$, fixed at the right end, 
Figure 1. From this it follows that Green's function is the influence function for the bending moment of a cantilever beam, well known to civil engineering.

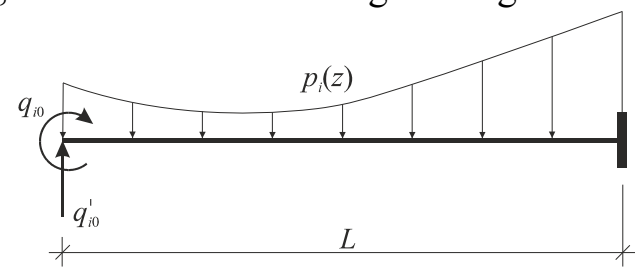

Figure 1. Fictitious Cantilever Beam

Differentiating Eq. 8 we get

$q_{i}^{\prime}(z)=\int s^{\prime}(z, \varsigma) p_{i}(\varsigma) d \varsigma+q_{i 0}^{\prime}$

where is

$s^{\prime}(z, \varsigma)=\left\{\begin{array}{cc}-1 & \varsigma \leq z \\ 0 & \varsigma>z\end{array}\right.$

influence function for transversal force of the cantilever beam.

\section{NUMERICAL SOLUTION}

The values of definite integral in Eq. 8 can be expressed approximately, using method for numerical integration.

Unknown function $p_{i}(z)$, which by static analogy with beam in bending represents the load, will be replaced with an equivalent static forces $P_{i, k}$ concentrated at selected points (nodes) $k(k=0,1$, $2, . ., M-1)$ of the equidistant spacing $\lambda$, so that the bending moments at these points, due to a given distributed load, are the same as the moments due to concentrated forces, Figure 2. In the case when the given load changes linearly from node to node, expressions for the concentrated forces are given by the following expressions

$$
\begin{aligned}
& P_{i, 0}=\frac{\lambda}{6}\left(2 p_{i, 0}+p_{i, 1}\right) \\
& P_{i, k}=\frac{\lambda}{6}\left(p_{i, k-1}+4 p_{i, k}+p_{i, k+1}\right) \\
& P_{i, M}=\frac{\lambda}{6}\left(p_{i, M-1}+2 p_{i, M}\right)
\end{aligned}
$$

where $p_{i, k}$ are the ordinates of function $p_{i}(\mathrm{z})$ at selected points $k$. Expressions Eq. 12 are well known in structural mechanics where a process of reducing a distributed load to equivalent concentrated forces is often employed.

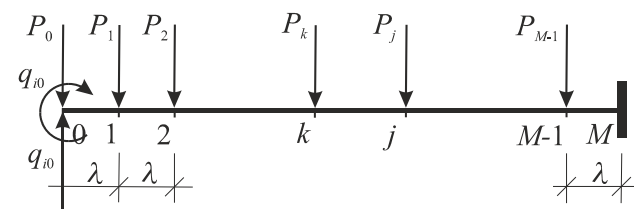

Figure 2. Substituting Concentrated Forces 
Eq. 8, taking into account their static sense, can be now represented in matrix form as

$\left[\begin{array}{c}\mathbf{q}_{1} \\ \hdashline \mathbf{q}_{2} \\ \hdashline \mathbf{q}_{3} \\ \hdashline \vdots \\ \hdashline \mathbf{q}_{M}\end{array}\right]=\left[\begin{array}{c:c|c:c:c}\lambda \mathbf{I} & & & \cdots & \\ \hdashline 2 \lambda \mathbf{I} & \lambda \mathbf{I} & & \cdots & \\ \hdashline 3 \lambda \mathbf{I} & 2 \lambda \mathbf{I} & \lambda \mathbf{I} & \cdots & \\ \hdashline \vdots & \vdots & \vdots & \ddots & \vdots \\ \hdashline M \lambda \mathbf{I} & (M-1) \lambda \mathbf{I} & (M-2) \lambda \mathbf{I} & \cdots & \lambda \mathbf{I}\end{array}\right]\left[\begin{array}{c}\mathbf{P}_{0} \\ \hdashline \mathbf{P}_{1} \\ \hdashline \mathbf{P}_{2} \\ \hdashline \vdots \\ \hdashline \mathbf{P}_{(M-1)}\end{array}\right]+\left[\begin{array}{c:c}\lambda \mathbf{I} & \mathbf{I} \\ \hdashline 2 \lambda \mathbf{I} & \mathbf{I} \\ \hdashline 3 \lambda \mathbf{I} & \mathbf{I} \\ \hdashline \vdots & \vdots \\ \hdashline M \lambda \mathbf{I} & \mathbf{I}\end{array}\right]\left[\begin{array}{c}\mathbf{q}_{0}^{\prime} \\ \mathbf{q}_{0}\end{array}\right]$

where $\mathbf{q}_{j}(j=1,2, \ldots, M)$ and $\mathbf{P}_{k}(k=0,2, \ldots, M-1)$ are the vectors of nodal "bending moments" and "concentrated forces" of the fictitious cantilever beam, all of which, in general, has three components.

Substituting Eqs. 12 to Eq. 13 we obtain

$\mathbf{Q}=\mathbf{S P}+\mathbf{L Q}_{0}$

or explicitly

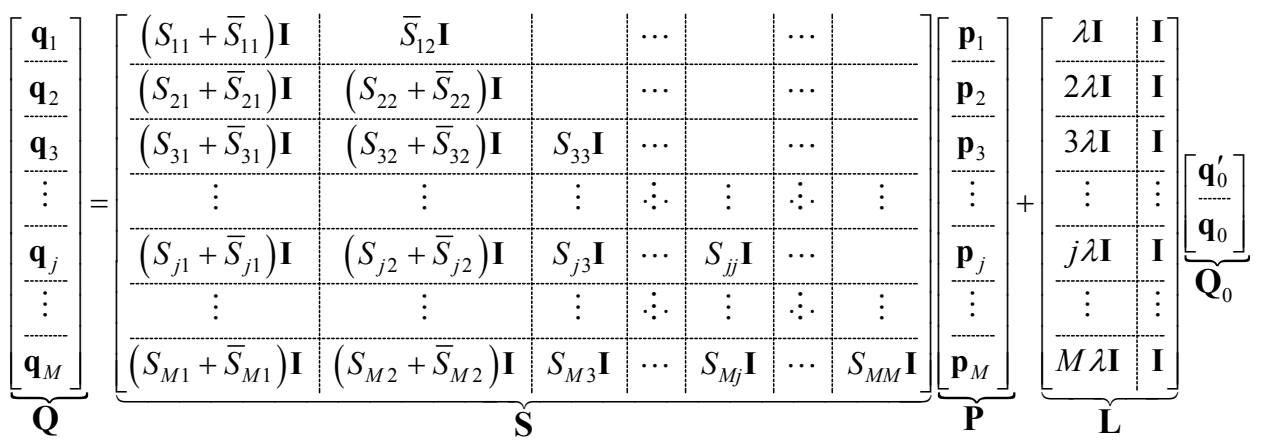

where

$$
\begin{aligned}
& S_{j k}=\left\{\begin{array}{cc}
-\lambda^{2} / 6 & j=k \\
0 & j<k \\
-(j-k) \lambda^{2} & j>k
\end{array}\right. \\
& \bar{S}_{j k}=\left\{\begin{array}{cc}
-\left(j-\frac{1}{3}\right) \lambda^{2} & k=1 \\
\frac{1}{2}\left(j-\frac{1}{3}\right) \lambda^{2} & k=2
\end{array}\right.
\end{aligned}
$$

Performing the Eq. 14 the ordinate of function $p_{i}(z)$ at point $k=0\left(p_{i 0}\right)$ is determined by linear extrapolation, so that $p_{i 0}=2 p_{i 1}-p_{i 2}$.

Differentiating Eq. 14 with respect to $z$, and applying the previous transformations, in a similar way we obtain

$\mathbf{Q}^{\prime}=\mathbf{S}^{\prime} \mathbf{P}+\mathbf{L}^{\prime} \mathbf{Q}_{0}$

or in a developed form 


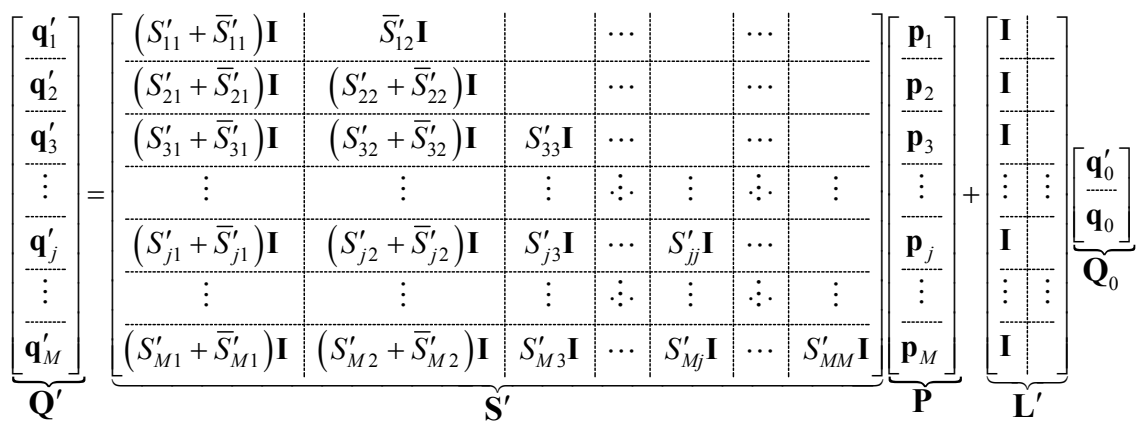

where

$$
\begin{aligned}
& S_{j k}^{\prime}=\left\{\begin{array}{cc}
-\lambda / 2 & j=k \\
0 & j<k \\
-\lambda & j>k
\end{array}\right. \\
& \bar{S}_{j k}^{\prime}=\left\{\begin{array}{cc}
-\lambda & k=1 \\
\lambda / 2 & k=2
\end{array}\right.
\end{aligned}
$$

Also, from Eq. 6 it follows

$$
\mathbf{Q}^{\prime \prime}=-\mathbf{P}
$$

Conditions that differential equations of motion of the axially loaded Timoshenko beam, Eqs. 4, are satisfied at all discrete points $j(j=1,2, \ldots, M)$, can be expressed as

$$
\mathbf{A}^{*} \mathbf{Q}^{\prime \prime}+\mathbf{B}^{*} \mathbf{Q}^{\prime}+\left(\mathbf{C}^{*}+\omega^{2} \mathbf{D}^{*}\right) \mathbf{Q}=\mathbf{0}
$$

where

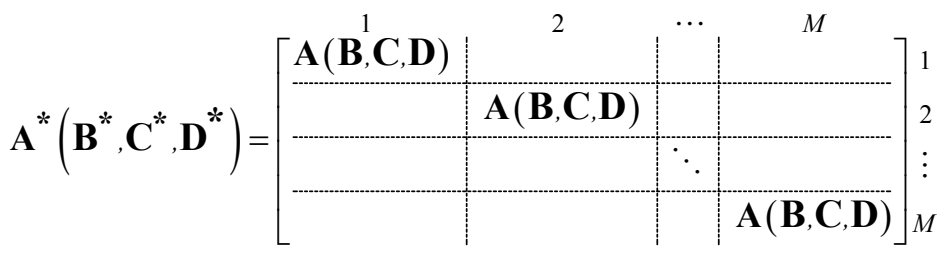

Substituting Eqs. 14, 17 and 20 into Eq. 21 yields

$$
\left[-\mathbf{A}^{*}+\mathbf{B}^{*} \mathbf{S}^{\prime}+\left(\mathbf{C}^{*}+\omega^{2} \mathbf{D}^{*}\right) \mathbf{S}\right] \mathbf{P}+\left[\mathbf{B}^{*} \mathbf{L}^{\prime}+\left(\mathbf{C}^{*}+\omega^{2} \mathbf{D}^{*}\right) \mathbf{L}\right] \mathbf{Q}_{0}=\mathbf{0}
$$

from which we obtain

$$
\mathbf{P}=-\mathbf{K}^{-1} \overline{\mathbf{L}} \mathbf{Q}_{0}
$$

where 


$$
\begin{aligned}
& \mathbf{K}=-\mathbf{A}^{*}+\mathbf{B}^{*} \mathbf{S}^{\prime}+\left(\mathbf{C}^{*}+\omega^{2} \mathbf{D}^{*}\right) \mathbf{S} \\
& \overline{\mathbf{L}}=\mathbf{B}^{*} \mathbf{L}^{\prime}+\left(\mathbf{C}^{*}+\omega^{2} \mathbf{D}^{*}\right) \mathbf{L}
\end{aligned}
$$

Taking into account Eqs. 15 and 18 we can establish a connection between the values of the vector $\mathbf{q}$ and $\mathbf{q}^{\prime}$ on the right and left end of the element

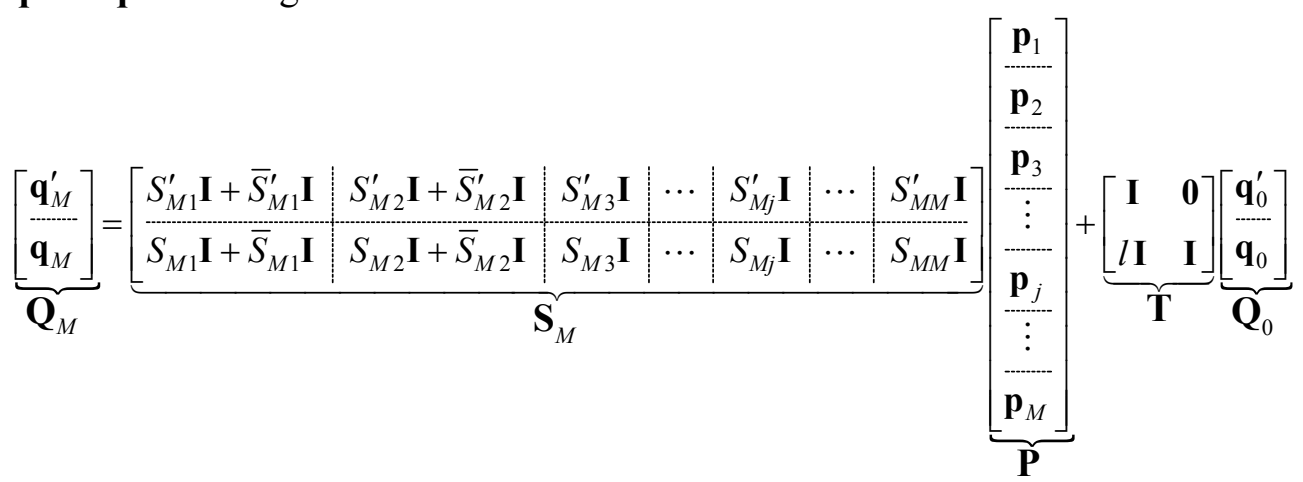

or

$$
\mathbf{Q}_{M}=\mathbf{S}_{M} \mathbf{P}+\mathbf{T} \mathbf{Q}_{0}
$$

Substituting Eq. 24 into Eq. 27 we get

$$
\mathbf{Q}_{M}=\left(-\mathbf{S}_{M} \mathbf{K}^{-1} \overline{\mathbf{L}}+\mathbf{T}\right) \mathbf{Q}_{0}
$$

At the beam ends, depending on the support conditions, boundary conditions are given by the forces and/or displacements. Consider the most general case of mixed boundary conditions at both ends of the beam. Taking into account that

$$
\begin{aligned}
& M=E I_{y} \psi^{\prime}+K \varphi^{\prime} \\
& Q=-P v^{\prime}+k F G\left(v^{\prime}-\psi\right) \\
& T=-P \frac{I_{s}}{\mu} \varphi^{\prime}+K \psi^{\prime}+G J \varphi^{\prime}
\end{aligned}
$$

we can establish the following relations on the left and right end of the element

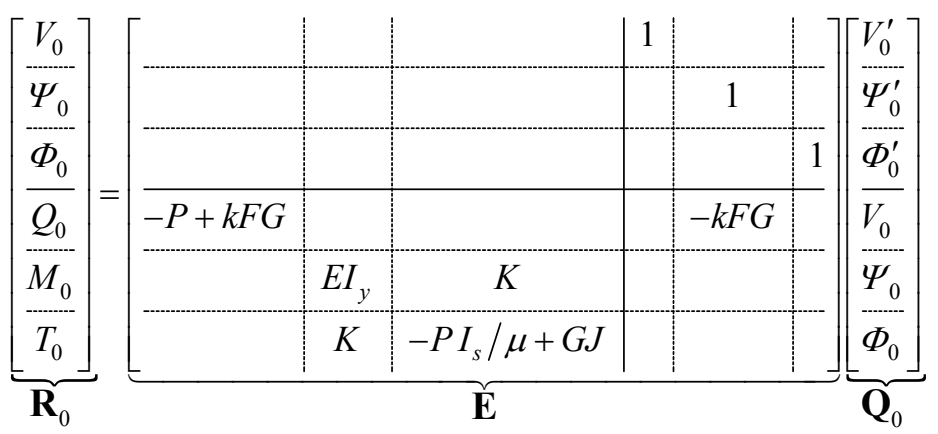




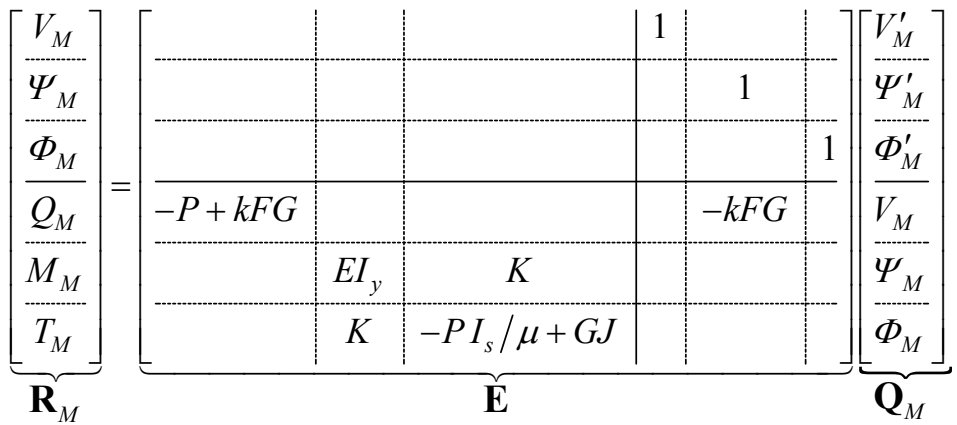

Or

$\mathbf{R}_{0}=\mathbf{E} \mathbf{Q}_{0}$

$\mathbf{R}_{M}=\mathbf{E} \mathbf{Q}_{M}$

Multiplying the left side of the matrices Eq. 28 with matrix $\mathbf{E}$ and taking into account the Eqs. 32 and 33 , we obtain

$$
\mathbf{R}_{M}=\mathbf{E}\left(-\mathbf{S}_{M} \mathbf{K}^{-1} \overline{\mathbf{L}}+\mathbf{T}\right) \mathbf{E}^{-1} \mathbf{R}_{0}
$$

or

$$
\mathbf{R}_{M}=\mathbf{F R}_{0}
$$

where

$$
\mathbf{F}=\mathbf{E}\left(-\mathbf{S}_{M} \mathbf{K}^{-1} \overline{\mathbf{L}}+\mathbf{T}\right) \mathbf{E}^{-1}
$$

This is a system of six linear homogeneous algebraic equations for the 12 unknowns $V_{0}, \Psi_{0}, \Phi_{0}, Q_{0}, M_{0}, T_{0}, V_{M}, \Psi_{M}, \Phi_{M}, Q_{M}, M_{M}, T_{M}$. If homogeneous boundary conditions at the ends of the beam, which number is 6 , enter into the Eq. 35 we get the homogeneous system of 6 equations with 6 unknowns. This system, representing an algebraic eigenvalue problem, can have a nonzero solution only when the determinant of the equation system vanishes, and the natural frequencies $\omega$ can be determined as the roots of this determinant. When the frequencies are substituted back into Eq. 35 the components of vector $\mathbf{R}_{0}$ can be determined to the multiplicative constant factor. Now combining the equations 32, 24 and 13 the mode shapes vector $\mathbf{Q}$, corresponding to the natural frequencies $\omega$ can be found.

\section{NUMERICAL EXAMPLES}

In this section, the introduced method will be employed in analyzing the free vibration of axially loaded cantilever composite Timoshenko beam with the following boundary conditions:

- The geometric boundary conditions at the cantilever end, $x=0$ $v=\psi=\varphi=0$

- The natural boundary conditions at the free end, $x=l$ 


$$
\begin{array}{lc}
\text { Bending moment }(M): & E I_{y} \psi^{\prime}+K \varphi^{\prime}=0 \\
\text { Shear force }(Q): & -P v^{\prime}+k F G\left(v^{\prime}-\psi\right)=0 \\
\text { Torque }(T): & -P \frac{I_{s}}{\mu} \varphi^{\prime}+K \psi^{\prime}+G J \varphi^{\prime}=0
\end{array}
$$

To demonstrate the applicability of the proposed method, the beam model studied by Kaya and Ozgumus [10] is solved as an illustrative example. It is a cantilever glass-epoxy composite beam with a rectangular cross section with width $12.7 \mathrm{~mm}$ and thickness $3.18 \mathrm{~mm}$. Unidirectional plies each having fibre angles of +15 are used in the analysis. The data used for the analysis are as follows:

bending rigidity $\left(E I_{y}\right)=0.2865 \mathrm{Nm} 2$;

torsional rigidity $(G J)=0.1891 \mathrm{Nm} 2$;

bending \pm torsion coupling rigidity $(K)=0.1143 \mathrm{Nm} 2$;

shear rigidity $(k F G)=6343.3 \mathrm{~N}$;

mass per unit length $(m)=0.0544 \mathrm{~kg} / \mathrm{m}$;

mass moment of inertia per unit length $\left(I_{s}\right)=0.7770 \times 10^{-6} \mathrm{kgm}$;

length of the beam $(l)=0.1905 \mathrm{~m}$.

$\rho I_{y}=4.584 \times 10^{-8} \mathrm{kgm}$

The first six natural frequencies of the above composite Timoshenko beam are calculate and numrical results are shown in Table 1, along with the natural frequencies of Kaya and Ozgumus

\begin{tabular}{|c|c|c|c|c|c|c|}
\hline \multirow[b]{3}{*}{ Mode } & \multicolumn{6}{|c|}{ Natural frequencies $[\mathrm{Hz}]$} \\
\hline & \multicolumn{2}{|c|}{$\mathrm{P}=0$} & \multicolumn{2}{|c|}{$\mathrm{P}=7.5$ (compression $)$} & \multicolumn{2}{|c|}{$\mathrm{P}=-7.5$ (tension) } \\
\hline & $\begin{array}{l}\text { Present } \\
\text { study }\end{array}$ & $\begin{array}{l}\text { Kaya and } \\
\text { Ozgumus }\end{array}$ & $\begin{array}{l}\text { Present } \\
\text { study }\end{array}$ & $\begin{array}{l}\text { Kaya and } \\
\text { Ozgumus }\end{array}$ & $\begin{array}{l}\text { Present } \\
\text { study }\end{array}$ & $\begin{array}{l}\text { Kaya and } \\
\text { Ozgumus }\end{array}$ \\
\hline 1 & 31.118 & 30.747 & 22.031 & 21.987 & 37.660 & 37.106 \\
\hline 2 & 193.028 & 189.779 & 184.799 & 181.495 & 200.890 & 197.572 \\
\hline 3 & 530.372 & 518.791 & 523.241 & 511.818 & 537.404 & 525.665 \\
\hline 4 & 648.368 & 648.169 & 646.506 & 648.047 & 650.227 & 648.495 \\
\hline 5 & 1013.914 & 986.199 & 1006.694 & 979.473 & 1021.075 & 992.878 \\
\hline 6 & 1618.624 & 1564.751 & 1611.020 & 1558.134 & 1626.180 & 1571.338 \\
\hline
\end{tabular}
[10].

Table 1. The First Xix Natural Frequencies of Composite Timoshenko Beam

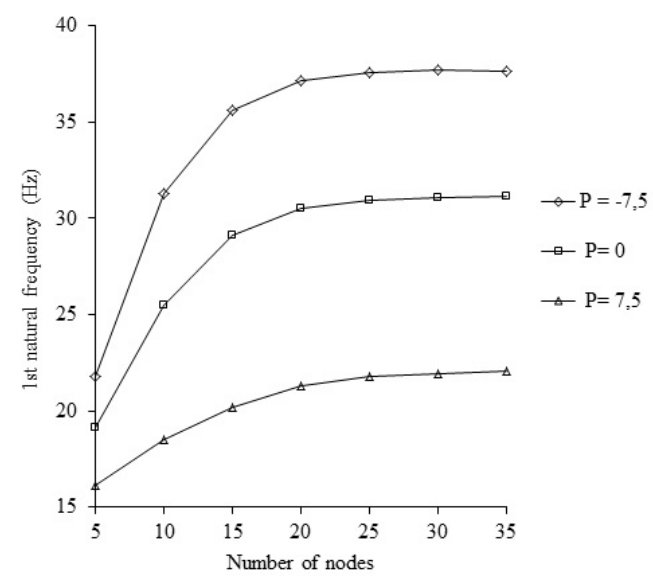

Figure 3. Convergence of the Natural Frequencies 
Close agreements in natural frequencies are obtained between the proposed method and method by Kaya and Ozgumus [10]. For $k=30$, the differences between the two methods are less than 3\%. The convergence of the first natural frequency for $\mathrm{P}=0, \mathrm{P}=7.5$ and $\mathrm{P}=-7.5$, is shown in the Fig. 3. It can be seen that the proposed methods converge fast-and a relatively small number of interior points are required for a good prediction of frequencies.

\section{CONCLUSIONS}

In this paper a numerical method is presented for the analysis of axially loaded composite Timoshenko beam which exhibits bending-torsion coupling. The essential steps of the proposed method includes transforming the basic governing differential equations of motion into integral equations, and then, using numerical procedure, it is possible to replace that equations with system of linear algebraic equations. The basic mathematical operation is simple and can be readily solved by the application of matrix calculus. Numerical verification demonstrates that the proposed method is reasonably accurate, i.e. the numerical approximations, in most cases, is accurate for quite low values of $k$.

Finally, it can be said that proposed method can serve as a convenient alternative to the similar numerical techniques in the analysis of coupled vibration of Timoshenko beam. Also it should be noted that the proposed method can be applied to all the problems of structural mechanics defined by a set of second-order ordinary differential equations of variable coefficients, with arbitrary boundary conditions, for example, to the problems of stability.

\section{ACKNOWLEDGMENT}

The present work has been supported by The Ministry of Education and Science of the Republic of Serbia (Project No. ON174027).

\section{REFERENCES}

[1] Ansari, R., Gholami, R. and Hosseini, K., "A Sixth-order Compact Finite Difference Method for Free Vibration Analysis of Euler-Bernoulli Beams", Mathematical Sciences, 2011, Vol. 5, No. 4, pp.307-320.

[2] Banerjee, J.R., "Dynamic Stiffness Formulation and Free Vibration Analysis of Centrifugally Stiffened Timoshenko Beams", Journal of Sound and Vibration, 2001, Vol. 247, No. 1, pp.97-115.

[3] Banerjee, J.R., Su, H. and Jayatunga, C., "A Dynamic Stiffness Element for Free Vibration Analysis of Composite Beams and Its Application to Aircraft Wings", Computers and Structures, 2008, Vol. 86, No. 6, pp.573-579.

[4] Berczynski, S. and Wroblewski T., "Vibration of Steel-Concrete Composite Beams Using the Timoshenko Beam Model", Journal of Vibration and Control, 2005, Vol. 11, No. 6, pp.829-848.

[5] Biscontin, G., Morassi A. and Wendel, P., "Vibrations of Steel-Concrete Composite Beams", Journal of Vibration and Control, 2000, Vol. 6, No. 5, pp.691-714.

[6] Borbón, F., Mirasso, A. and Ambrosini, D., "A Beam Element for Coupled Torsional-flexural Vibration of Doubly Unsymmetrical Thin Walled Beams Axially Loaded", Computers and Structures, 2011, Vol. 89, No. 13-14, pp.1406-1416. 
[7] Byron, F.W. and Fuller, R.W., "Mathematics of Classical and Quantum Physics“, Dover Publications, Inc., New York, 1992.

[8] Fu-le, L. and Zhi-zhong, S., "A Finite Difference Scheme for Solving the Timoshenko Beam Equations with Boundary Feedback", Journal of Computational and Applied Mathematics, 2007, Vol. 200, No. 2, pp.606- 627.

[9] Hajdin, N., "A Method for Numerical Solution of Boundary Value Problems", Trans. Civ. Engng. Dept,. 1958, No. 4, pp.1-58.

[10] Kaya, M.O. and Ozgumus Ozdemir, O., "Flexural-torsional-coupled Vibration Analysis of Axially Loaded Closed-section Composite Timoshenko Beam by Using DTM", Journal of Sound and Vibration, 2007, Vol. 306, No. 3-5, pp.495-506.

[11] Li J., Shen, R., Hua, H. and Jin, X., "Bending-torsional Coupled Dynamic Response of Axially Loaded Composite Timoshenko Thin-walled Beam with Closed Crosssection", Composite Structures, 2004, Vol. 64, No. 1, pp.23-35.

[12] Liu, Z., Yin, Y., Wang, F., Zhao, Y. and Cai, L., "Study on Modified Differential Transform Method for Free Vibration Analysis of Uniform Euler-Bernoulli Beam", Structural Engineering and Mechanics, An Int'1 Journal, 2013, Vol. 48, No. 5, pp.697-709.

[13] Mirtalaie, S.H., Mohammadi, M., Hajabasi, M.A. and Hejripour F., "Coupled Lateral-torsional Free Vibrations Analysis of Laminated Composite Beam using Differential Quadrature Method", Word Academy of Science, Engineering and Technology, 2012, No. 67, pp.117-122.

[14] Pagani, A., Boscolo, M., Banerjee, J.R. and Carrera, E., "Exact Dynamic Stiffness Elements Based on One-dimensional Higher-order Theories for Free Vibration Analysis of Solid and Thin-walled Structures", Journal of Sound and Vibration, 2013, Vol. 332, No. 23, pp.6104-6127.

[15] Pan, D., Chen, G. and Lou, M., "A Modified Modal Perturbation Method for Vibration Characteristics of Non-prismatic Timoshenko Beams", Structural Engineering and Mechanics, An Int'l Journal, 2011, Vol. 40, No. 5, pp.689-703.

[16] Rajasekaran, S., "Free Vibration of Centrifugally Stiffened Axially Functionally Graded Tapered Timoshenko Beams Using Differential Transformation and Quadrature Methods", Applied Mathematical Modelling, 2013, Vol. 37, No. 6, pp.440-4463.

[17] Reddy, J.N., "On Locking-free Shear Deformable Beam Finite Elements", Comput. Methods Appl. Mech. Engrg., 1997, Vol. 149, pp.113-132.

[18] Vo, T.P., Lee, J. and Lee, K., "On Triply Coupled Vibrations of Axially Loaded Thin-walled Composite Beams", Computers and Structures, 2010, Vol. 88, No. 3-4, pp.144-153. 